Research Article

\title{
Clinicoanatomical Study of Foramen Magnum and its Significance in Surgeries
}

\author{
Sachin Patil', Dharmendra Kumar
}

${ }^{1}$ Assistant Professor, Department of Anatomy, ANIIMS, Port Blair, Andaman and Nicobar Islands, India.

${ }^{2}$ Associate Professor \& Head, Department of Physical Medicine and Rehabilitation, ANIIMS, Port Blair, Andaman and Nicobar Islands, India.

DOI: https://doi.org/10.24321/2454.8642.201905

\section{I $\quad \mathbf{N} \quad \mathbf{F} \quad \mathbf{O}$}

\section{Corresponding Author:}

Dharmendra Kumar, Department of Physical Medicine and Rehabilitation, ANIIMS, Port Blair, Andaman and Nicobar Islands, India.

E-mail Id:

dharmendra744101@gmail.com

\section{Orcid Id:}

https://orcid.org/0000-0001-9722-5107

How to cite this article:

Patil S, Kumar D. Clinicoanatomical Study of Foramen Magnum and its Significance in Surgeries. Rec Adv Path Lab Med 2019; 5(2): 5-7.

Date of Submission: 2019-07-15

Date of Acceptance: 2019-08-31

\section{$\begin{array}{lllllllllllllll}\mathbf{A} & \mathbf{B} & \mathbf{S} & \mathbf{T} & \mathbf{R} & \mathbf{A} & \mathbf{C} & \mathbf{T}\end{array}$}

Introduction: The dimensions of the Foramen Magnum are surgically important because the compression of any structure passing through it can lead to severe complications.

Materials and Methods: One hundred and five dried human skulls were classified as round, oval, and egg, pentagonal, hexagonal and irregular. The antero-posterior and transverse diameters were measured by using digital Vernier callipers. The Foramen Magnum Index was calculated by the formula: Anteroposterior diameter/ Transverse diameter.

Results: In our study, the irregular shaped Foramen Magnum was found to be the highest in incidence. The mean antero-posterior and transverse diameters of the foramen magnum were recorded as $37.65 \mathrm{~mm}$ and $32.44 \mathrm{~mm}$ while the foramen magnum index was 88.68 .

Conclusion: The morphological and morphometric measurements of foramen magnum of skulls are of forensic importance. The neurosurgeons, orthopedicians and radiologists should be aware of these variations to avoid any complications during surgeries or any other procedures.

Keywords: Foramen Magnum, Morphometry, Occipital Condyles

\section{Introduction}

Foramen magnum is an important communication between the posterior cranial fossa and the vertebral canal. The contents passing through foramen magnum are the medulla oblongata, the vertebral artery and the spinal accessory nerves. ${ }^{1}$ The dimensions of the Foramen Magnum are surgically important because the compression of any structure passing through it can lead to severe complications. The shape and dimensions of foramen magnum may change with developmental anomalies, herniation of surrounding structures or tumors like meningiomas. ${ }^{2}$ The shape and size abnormalities are associated with congenital syndromes like Arnold Chiari syndrome. The diameter of foramen magnum has gender variations which has important role in forensic medicine. ${ }^{3}$ The foramen magnum index and cranial index are important parameters that are used in craniometery for racial comparison. ${ }^{4}$ Also, the knowledge of surgical anatomy of foramen magnum is very useful for neurosurgeons, orthopedicians and radiologists. ${ }^{5}$

\section{Materials and Methods}

One hundred and five dried human skulls of unknown age and sex were collected from the bone bank of our medical college and examined for the present study. The 
different shapes of the foramen magnum were noted by gross examination and classified as round, oval, and egg, pentagonal, hexagonal and irregular (Figure 1). The anteroposterior and transverse diameters were measured by using digital Vernier calliper. The anteroposterior diameter of the Foramen magnum was measured as the distance between basion to the opisthion and the transverse diameter of the Foramen magnum was measured as the distance between its lateral margins at the point of greatest lateral curvature (Figure 2). The Foramen Magnum Index was calculated by the formula: Anteroposterior diameter/Transverse diameter.

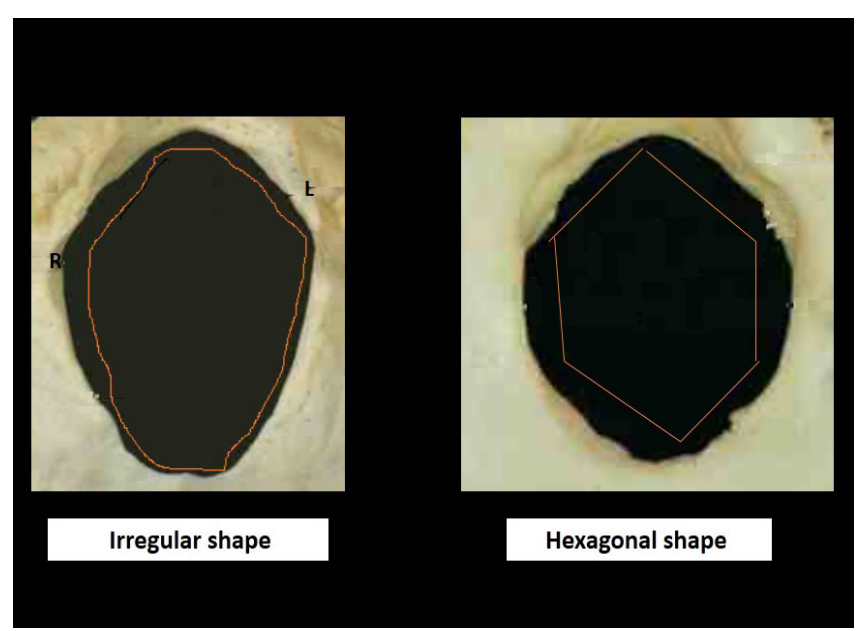

Figure I.The most common and least common shape of foramen magnum

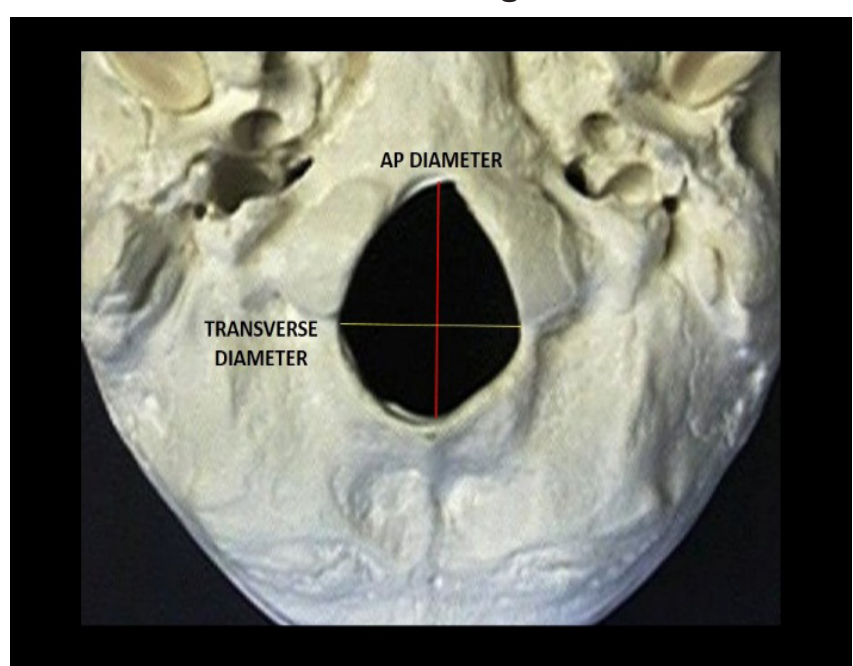

Figure 2.The measurements of anteroposterior and transverse diameter of foramen magnum
Table I.Incidence of various shapes of foramen magnum

\begin{tabular}{|c|c|}
\hline $\begin{array}{c}\text { Morphological variants of Foramen } \\
\text { Magnum }\end{array}$ & $\begin{array}{c}\text { Percentage and } \\
\text { number }\end{array}$ \\
\hline Irregular shape & $33.6 \%(32)$ \\
\hline Round shape & $22.05 \%(21)$ \\
\hline Oval shape & $18.9 \%(18)$ \\
\hline Egg shape & $16.8 \%(16)$ \\
\hline Pentagonal shape & $10.5 \%(10)$ \\
\hline Hexagonal shape & $8.4 \%(8)$ \\
\hline
\end{tabular}

Table 2. Mean values of foramen magnum diameters and foramen magnum index

\begin{tabular}{|c|c|}
\hline Mean anteroposterior diameter & $37.65 \mathrm{~mm}$ \\
\hline Mean transverse diameter & $32.44 \mathrm{~mm}$ \\
\hline Mean foramen magnum index & 88.68 \\
\hline
\end{tabular}

\section{Result}

In our study, among the various shapes observed the irregular shaped Foramen Magnum was found to be the highest in incidence. The incidence of various shapes of Foramen Magnum in skulls are shown in Table 1. The mean antero-posterior and transverse diameters of the foramen magnum were recorded as $37.65 \mathrm{~mm}$ and $32.44 \mathrm{~mm}$ while the foramen magnum index was 88.68 (Table 2).

\section{Discussion}

The foramen magnum, is an important link between spine and skull and it has a close relationship to important structures like brain stem and the spinal cord. ${ }^{6}$ Number of studies have been conducted on foramen magnum. The foramen magnum is an important the surgical landmark in transcondylar approach for a safe occipital condyle resection. $^{7}$

\section{Shape of the Foramen Magnum}

The previous studies on foramen magnum have reported variations in the shape of foramen magnum namely, oval, round, tetragonal, irregular, hexagonal, egg and pentagonal. ${ }^{8}$ Table 3 shows the incidence of the shape of the foramen magnum in different studies. ${ }^{9,}{ }^{10}$ In the present study the highest incidence was of irregularly shaped foramen magnum (33.6\%) while lowest incidence was of hexagonal shape (8.4\%).

Table 3.Comparison of percentage of incidence of different shapes of foramen magnum-studies from India

\begin{tabular}{|c|c|c|c|c|c|c|}
\hline Study & Irregular & Oval & Egg & Round & Pentagonal & Hexagonal \\
\hline Chethan P et al. 53 skulls $^{17}$ & $15.1 \%$ & $15.1 \%$ & $18.9 \%$ & $22.6 \%$ & $3.8 \%$ & $5.6 \%$ \\
\hline Ganapathy A et al. 100 skulls $^{14}$ & $32.0 \%$ & $6.0 \%$ & $12.0 \%$ & $15.0 \%$ & $3.0 \%$ & $21.0 \%$ \\
\hline Present study & $33.6 \%$ & $18.9 \%$ & $16.8 \%$ & $22.05 \%$ & $10.5 \%$ & $8.4 \%$ \\
\hline
\end{tabular}




\section{Size of the Foramen Magnum}

The anteroposterior (sagittal) diameter of foramen magnum is more than the transverse diameter. ${ }^{11}$ The values of anteroposterior and transverse diameter in this study were in line with the previous study. ${ }^{12,13}$ The normal range for the anteroposterior and transverse diameter measurements of the Foramen magnum are $28 \mathrm{~mm}$ and $47 \mathrm{~mm}$, and for the transverse diameter measurements $21 \mathrm{~mm}$ and 41.0 $\mathrm{mm} .{ }^{14,15}$ The foramen magnum index was 88.68 which was similar to other previous studies. ${ }^{16}$

\section{Conclusion}

The morphological and morphometric measurements of foramen magnum of skulls are of forensic importance. Lots of variations are seen in shape and size of foramen magnum as per studies conducted on foramen magnum including the current study. The neurosurgeons, orthopedicians and radiologists should be aware of these variations to avoid any complications during surgeries or any other procedures.

\section{Acknowledgement: None \\ Conflict of Interest: None \\ References}

1. Tubbs RS, Griessenauer CJ, Loukas M et al. Morphometric analysis of the foramen magnum: An anatomic study. Neurosurgery 2010; 66: 385-8.

2. Macaluso PJ Jr. Metric sex determination from basal region of the occipital bone in a documented French sample. Bull Mem Soc Anthropol Paris. 2011; 23: 19-26.

3. Natsis K, Piagkou M, Skotsimara G, et al. A morphometric anatomical and comparative study of the foramen magnum region in a Greek population. Surg Radiol Anat. 2013; 35: 925-34.

4. Lyrtzis Ch, Piagkou M, Gkioka A, et al. Foramen magnum, occipital condyles and hypoglossal canals morphometry: anatomical study with clinical implications. Folia Morphol. 2017; 76(3): 446-57.

5. Manoel C, Prado FB, Caria PHF, et al. Morphometric analysis of the foramen magnum in human skulls of Brazilian individuals: its relation to gender. Braz J Morphol Sci. 2009; 26(2):104-8.

6. Ukoha U, Egwu OA, Okafor IJ, et al. Sexual dimorphism in the foramen magnum of Nigerian Adult. Int J Biol Med Res. 2011; 2(4): 878-81.

7. Osunwoke EA, Oladipo GS, Gwunireama IU, et al. Morphometric analysis of the foramen magnum and jugular foramen in adult skulls in southern Nigerian population. Am J Sci Ind Res. 2012; 3: 446-8.

8. Deshmukh AG, Devershi DB. Comparison of cranial sex determination by univariate and multivariate analysis. J Anat Soc India 2006; 55(2): 48-51.

9. Kanodia G, Parihar V, Yadav YR, et al. Morphometric analysis of posterior fossa and foramen magnum. J
Neurosci Rural Pract. 2012; 3(3): 261-6.

10. Jain D, Jasuja OP, Nath $S$. Evaluation of foramen magnum in sex determination from human crania by using discriminant function analysis. Elective Medicine Journal 2014; 2(2): 89-92.

11. Patel R, Mehta CD. Morphometric study of foramen magnum at the base of human skull in South Gujarat. IOSR-JDMS 2014; 13(6) Ver. IV: 23-5.

12. Solan S. Morphometric analysis of foramen magnum and occipital condyles in human skull among eastern population-a case study. Indian Journal of Applied Research 2015; 5(9): 187-9.

13. Babu YPR, Kanchan T, Attiku Y, et al. Sex estimation from foramen magnum dimensions in an Indian population. J Forensic Leg Med. 2012; 19(3): 162-167.

14. Veeramani R, Manjunath KY, Amirthalingam U. Morphological and morphometric study of variations in the shape and size of the foramen magnum of human skulls. International Journal of Anatomy, Radiology and Surgery 2018; 7(2): A001-8.

15. Shanthi $\mathrm{CH}$, Lokanadham S. Morphometric study on foramen magnum of human skulls. Medicine Science 2013; 2(4): 792-798.

16. Shepur MP, Magi M, Nanjundappa B, et al. Morphometric analysis of foramen magnum. Int J Anat Res. 2014; 2(1): 249-255.

17. Chethan P, Prakash KG, Murlimanju BV, Prashanth KU, Prabhu LV, Saralaya VV, et al. Morphological analysis and morphometry of the foramen magnum: an anatomical investigation. Turk Neurosurg 2012; 22: 416-419. 